\title{
Descemet's Membrane Detachment: An Intraoperative Complication in Cataract Surgery with Phacoemulsification
}

This article was published in the following Dove Press journal:

International Medical Case Reports Journal

\section{Ana Luisa González (D) \\ Fermín Silva \\ Robinson Barrientos (ID \\ Fabricio Paredes}

Department of Ophthalmology, Research Department Clínica La Luz, I I48 Lima, Peru
Correspondence: Ana Luisa González Department of Ophthalmology, Research Department Clínica La Luz, Av. Arequipa, I 48 Lima, Peru

Tel +51947273992

Email Dra.analuisagonzalez88@gmail.com

\begin{abstract}
Descemet's membrane detachment (DMD) is a complication fundamentally associated with cataract surgery, the subclinical presentation being higher than expected. There are many varied treatments, from simple observation to penetrating keratoplasty. We present a case report of a 78-year-old male patient, without comorbidities, who underwent cataract surgery with phacoemulsification plus intraocular lens implantation in the capsular bag of the left eye. During the intraoperative procedure, he presented a DMD (height of $350 \mathrm{um}$ and length of $3 \mathrm{~mm}$ in Zone 1 according to the HELP algorithm), managed with adaptive viscoelastic under the soft-shell technique in the same operative act, injection of iso-expansile SF6 (20\%) intracameral plus postural positioning for 2 hours carried out 48 hours after surgery plus intensive topical treatment with hypertonic sodium chloride and steroidal anti-inflammatory drugs. At 72 hours after the operation of the application of the gas bubble, he presented with a transparent cornea and a bestcorrected visual acuity of 20/80, which finally for his ophthalmological control at 8 weeks presented definitive resolution of the case in the AS-OCT and with a BCVA of 20/30.
\end{abstract}

Keywords: descemet membrane detachment, anterior segment coherence tomography, ultrabiomicroscopy

\section{Introduction}

The Descemet membrane is a basement membrane for corneal endothelial cells, which play a fundamentally important role in maintaining corneal integrity and transparency. ${ }^{1,2}$

Descemet's membrane detachment (DMD) was described by Weve in 1927 and more systematically by Bernard Samuels in 1928. Scheie in 1964 characterized it as a potentially dangerous complication for vision. ${ }^{2}$ It is associated as a complication to infrequent cataract surgery during the intraoperative or more frequently in the postoperative period. In addition, it has multiple main etiologies as a risk factor, including advanced age, Fuchs dystrophy, prolonged surgical time, irregular clear corneal incisions. $^{3}$

To aid the clinical diagnosis and treatment of Descemet's membrane detachment, new technologies such as UBM ultrabiomicroscopy and anterior segment coherence tomography (AS-OCT) are very useful. They can be classified into three types: simple, symmetric and complete detachment. ${ }^{4,5}$

Most detachments are peripheral and resolve spontaneously, large and central DMD, if not treated properly, can cause decompensation and opacification of the cornea. ${ }^{6}$ Recently, Kumar et al developed an algorithm for classifying and assigning 
DMD treatment called HELP (Height, extent, length and pupil) based on the dimensions of the DMD measured by AS-OCT and its extension based on 3 corneal zones that the authors delimited. ${ }^{7}$

Treatment is varied, from observation, pneumatic descemetopexy with application of $20 \%$ sulphur hexafluoride (SF6) or 14\% perfluoropropane (C3F8) intracameral injection, to considering penetrating keratoplasty, DMEK or DSAEK. ${ }^{8,9}$

\section{Case Presentation}

A 78-year-old male patient, with no significant history, underwent cataract surgery with phacoemulsification at La Luz Clinic in Lima-Peru. The reported case complied with the Declaration of Helsinki. The ethics committee and institutional review board of Clínica La Luz approved the publication of the details of the case and the patient gave his informed consent in writing for the details of the case and the images presented to be published. The patient underwent cataract surgery with phacoemulsification plus intraocular lens implantation of the left eye. Simultaneous incisions were made in the clear cornea. Intracameral anesthesia was applied, then trypan blue, balanced saline solution (BSS) was placed, and after placing the adaptive viscoelastic, a separation of the descemet membrane was observed greater than at 12 hours and less than at 6 hours Figure 1A.

Before the observation of the detachment and to be able to continue with the surgery, the soft-shell technique was performed to protect the corneal endothelium and the descemet membrane, performing a paracentesis at 12 o'clock so that both layers of the descemet membrane were united, and in this way continuous with surgery, performing continuous circular capsulorhexis, and phacoemulsification was continued with low parameters, viscoelastic was placed again to introduce the intraocular lens very delicately Figure 1B. At the time, there was no SF6 at $20 \%$ or $\mathrm{C} 3 \mathrm{~F} 8$ at $14 \%$, so it was considered to leave the patient with an air bubble, which remained on day 1 postoperatively, with BCVA of hand movement. AS-OCT was requested to show the adhesion of the descemet membrane to the endothelium, a central undulating flap and a hanging flap were noted at the level of the main incision, in addition to stromal edema (height of 350 microns and length of $3 \mathrm{~mm}$ in Zone 1 according to HELP algorithm) Figure 2. Therefore, 48 hours postoperatively for injection of isoexpansile SF6 (20\%) intracameral plus intensive topical treatment with hypertonic sodium chloride and steroidal anti-inflammatory drugs, plus postural positioning for 2 hours.

At 72 hours postoperatively after the application of the gas bubble, a better corrected visual acuity of $20 / 80$ is presented, in the biomicroscopy, clear cornea, anterior chamber formed, with gas bubble present, centered intraocular lens, pressure intraocular $14 \mathrm{mmHg}$. Figure 3A. ASOCT, adhered descemet membrane Figure 3B. It was evaluated at 8 weeks with a new AS-OCT and the descemet membrane remained attached Figure 4. This was resolved successfully, maintaining a final best-corrected visual acuity of 20/30 (Supplementary Video S1 of the surgery).

\section{Discussion}

Descemet's membrane detachment (DMD) is a rare complication intraoperatively and more frequently after cataract surgery. Scheie in 1964 characterized it as a potentially dangerous complication for vision. ${ }^{2,10}$ The characteristic clinical sign is severe persistent corneal edema shortly after surgery with no spontaneous improvement. Descemet's membrane can sometimes be seen partially floating in the anterior chamber. AS-OCT can help determine the extent of DMD. ${ }^{11}$ The decision to choose a conservative watch-and-wait approach or surgical intervention depends on the height, length, and extent of the detachment, as well as the location. Likewise, intraoperatively, the soft-shell technique allows us to continue the surgery protecting the endothelium. ${ }^{12}$ Larger detachments require surgical treatment, and the first-line treatment should be descemetopexy by injection of air into the anterior chamber of the eye. That is why in our case we decided to use an air bubble as we did not have SF6 at $20 \%$ or $\mathrm{C} 3 \mathrm{~F} 8$ at $14 \%$ at that time. But when observing postoperatively that the DM was not completely attached, it was decided to apply $20 \%$ SF6 in iso-expansile concentration as many authors recommend and maintain a supine position for 2 hours. And it could be resolved successfully by giving her surveillance until 8 weeks after surgery. 5,9

Several retrospective analysis studies have found that descemetopexy represents a safe and effective option (reapplication in $71-87.5 \%$ of cases), which is why opting for this option emerged as the safest in view of the high postoperative success rate. ${ }^{3,9}$ However, there is no solid evidence about which gas to perform Descemetopexy. ${ }^{2}$ Reapplication of DMD with sodium hyaluronate has also been reported as effective (as has suture fixation). 

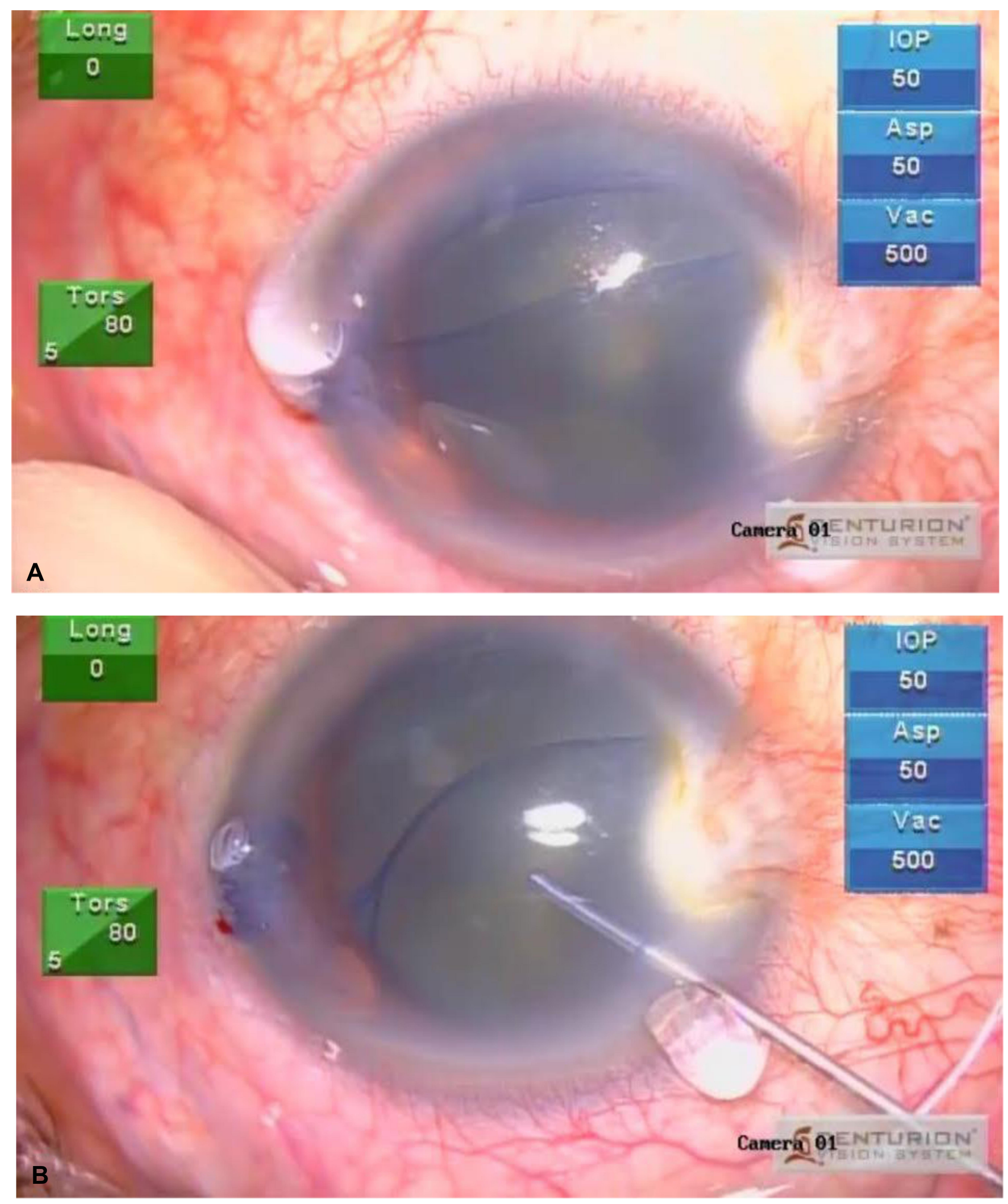

Figure I (A) You can see the separation and detachment of the Descemet membrane. (B) Soft-shell technique was performed to protect the endothelium. 


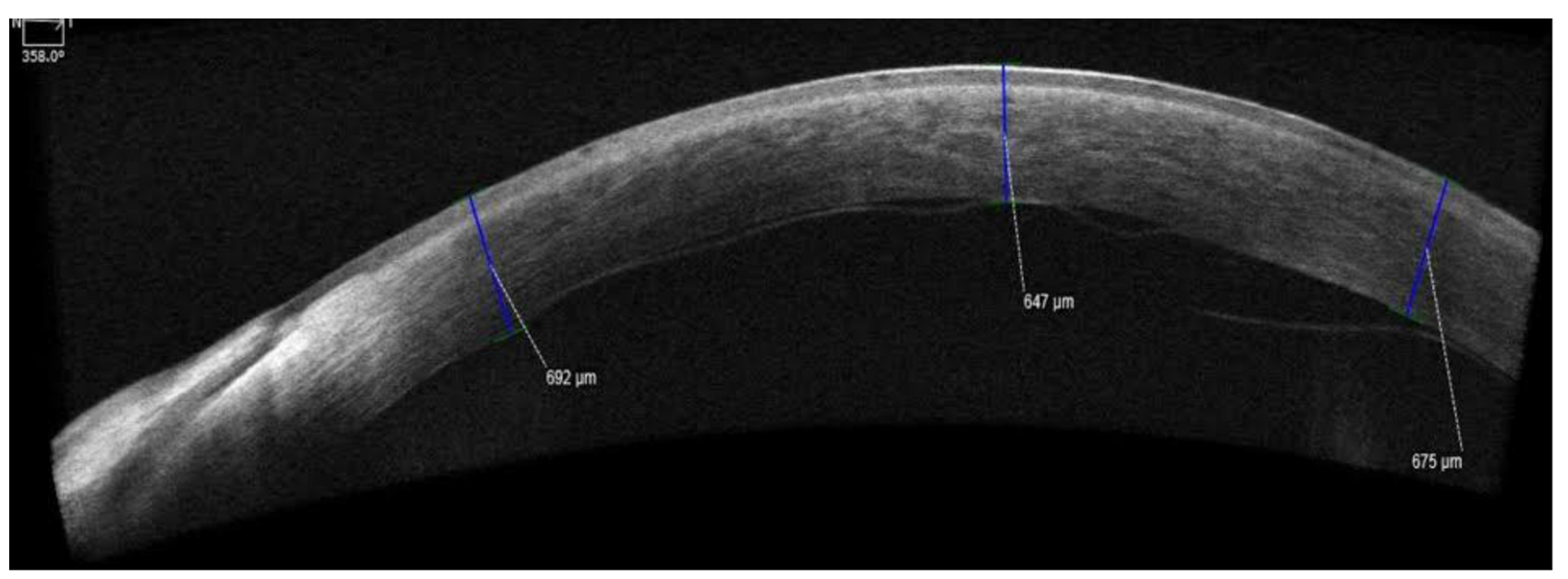

Figure 2 Descemet's membrane detached in a central and peripheral pendant wavy shape, with stromal edema.
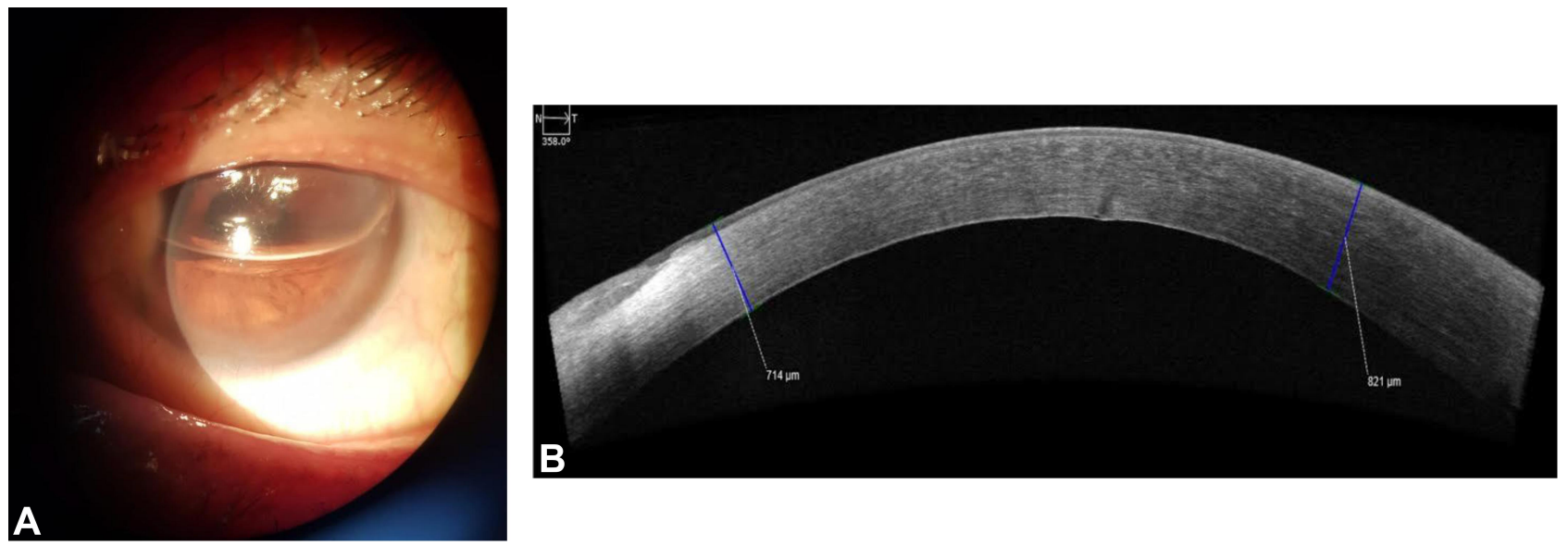

Figure 3 (A) In postoperative clear cornea, with gas bubble present. (B) AS -OCT- adhered Descemet membrane.

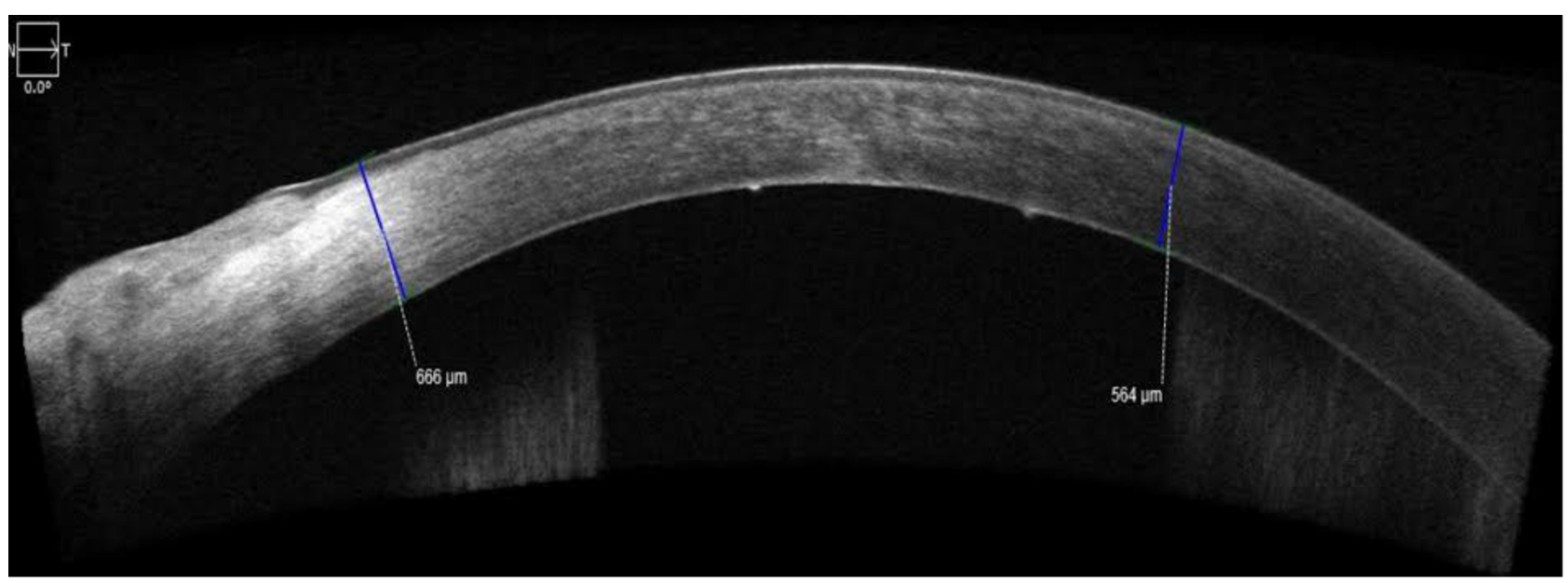

Figure 4 At 8 weeks after gas bubble application, the Descemet membrane remained adhered. 
Penetrating keratoplasty and Descemet's membrane endothelial keratoplasty are often considered last-line procedures. $^{13,14}$

\section{Acknowledgments}

The authors thank the patient for his acceptance with the informed consent, to carry out the realization of this case.

\section{Disclosure}

The authors report no conflicts of interest in this work.

\section{References}

1. Singhal D, Sahay P, Goel S, Asif MI, Maharana PK, Sharma N. Descemet membrane detachment. Surv Ophthalmol. 2020;65 (3):279-293. doi:10.1016/j.survophthal.2019.12.006

2. Benatti CA, Tsao JZ, Afshari NA. Descemet membrane detachment during cataract surgery: etiology and management. Curr Opin Ophthalmol. 2017;28(1):35-41. doi:10.1097/ICU.0000000000000332

3. Odayappan A, Shivananda N, Ramakrishnan S, Krishnan T, Nachiappan S, Krishnamurthy S. A retrospective study on the incidence of post-cataract surgery descemet's membrane detachment and outcome of air descemetopexy. $B r \quad J$ Ophthalmol. 2018;102 (2):182-186. doi:10.1136/bjophthalmol-2016-309766

4. Guo P, Pan Y, Zhang Y, et al. Study on the classification of descemet membrane detachment after cataract surgery with AS-OCT. Int J Med Sci. 2018;15(11):1092-1097. doi:10.7150/ijms.26972

5. Singh A, Vanathi M, Sahu S, Devi S. Intraoperative OCT assisted descemetopexy with stromal vent incisions and intracameral gas injection for case of non-resolving descemet's membrane detachment. $B M J$ Case Rep. 2017;2017. doi:10.1136/bcr-2016-217268
6. Dua HS, Sinha R, D'Souza S, et al. "Descemet membrane detachment": a novel concept in diagnosis and classification. $\mathrm{Am}$ J Ophthalmol. 2020;218:84-98. doi:10.1016/j.ajo.2020.05.038

7. Kumar DA, Agarwal A, Sivanganam S, Chandrasekar R. Height-, extent-, length-, and pupil-based (HELP) algorithm to manage post-phacoemulsification descemet membrane detachment. $J$ Cataract Refract Surg. 2015;41(9):1945-1953. doi:10.1016/j.jcrs. 2015.01.020

8. Sharma A, Singh SK, Bhutia PL, Pant R. Perfluoropropane (C3F8) injection for descemet's membrane detachment in cataract surgery. Nepal J Ophthalmol. 2015;7(1):74-78.

9. Ti S-E, Chee S-P, Tan DTH, Yang Y-N, Shuang SL. Descemet membrane detachment after phacoemulsification surgery: risk factors and success of air bubble tamponade. Cornea. 2013;32(4):454-459. doi:10.1097/ICO.0b013e318254c045

10. Xie W, Xu Y, Yao Y-F. Descemet's membrane detachment with schisis induced by phacoemulsification. Optom Vis Sci. 2016;93 (12):1562-1566. doi:10.1097/OPX.0000000000000993

11. Díaz A, Vicente MP, Tarragó E, Pascual J, Almela MA. Desprendimiento de la membrana de Descemet como complicación intraquirúrgica de la cirugía de la catarata. Rev Mex Oftalmol. 2014;88(4):186-188. doi:10.1016/j.mexoft.2014.05.001

12. Arshinoff SA, Norman R. Tri-soft shell technique. $J$ Cataract Refract Surg. 2013;39(8):1196-1203. doi:10.1016/j.jcrs.2013.06.011

13. Sonmez K, Ozcan PY, Altintas AGK. Surgical repair of scrolled descemet's membrane detachment with intracameral injection of $1.8 \%$ sodium hyaluronate. Int Ophthalmol. 2011;31(5):421-423. doi:10.1007/s10792-011-9473-5

14. Keye P, Reinhard T, Maier P. Treatment of descemet's membrane detachment after cataract surgery: successful visual recovery by repeated injection of air into the anterior chamber. Ophthalmol Z Dtsch Ophthalmol Ges. 2020;117(7):700-703. doi:10.1007/s003 47-020-01107-4

\section{Publish your work in this journal}

The International Medical Case Reports Journal is an international, peer-reviewed open-access journal publishing original case reports from all medical specialties. Previously unpublished medical posters are also accepted relating to any area of clinical or preclinical science. Submissions should not normally exceed 2,000 words or 4 published pages including figures, diagrams and references. The manuscript management system is completely online and includes a very quick and fair peer-review system, which is all easy to use. Visit http://www.dovepress.com/testimonials.php to read real quotes from published authors. 